\title{
A INOVAÇÃO DO MAL ESCRITO: LIMA BARRETO E ROBERTO ARLT
}

\section{THE INNOVATION OF POORLY WRITTEN: LIMA BARRETO AND ROBERTO ARLT}

\section{Keli Pacheco*}

RESUMO: Lima Barreto e Roberto Arlt são acusados, por parte da crítica, de escreverem mal. Ambos exerciam a função de colunistas de jornal como meio de amparar a família. Esta dupla jornada, a dedicação às artes e, ao mesmo tempo, à sobrevivência, suscita a discussão sobre a relação entre o 'ordinário' do trabalho e a 'excepcionalidade' artística. Procuramos elaborar uma discussão que aborda o mal escrever como um importante modo de questionamento da instituição literária e do mito de autor.

PALAVRAS-CHAVE: Inovação. Mal escrito. Lima Barreto. Roberto Arlt.

ABSTRACT: Lima Barreto and Roberto Arlt are accused, by the critics, of bad writing. Both of them were working as newspaper columnists to support their families. This double journey, the dedication to the arts, and at the same time, to the survival, raises the discussion about the relation between the 'ordinary' intrinsic of the work and the artistic 'exceptionality'. We try to elaborate a discussion that approaches the bad writing as an important way to question the literary institution and the author myth.

KEYWORDS: Innovation. Poorly written. Lima Barreto. Roberto Arlt.

Professora Adjunta do Departamento de Letras Vernáculas e do Mestrado em Linguagem, Identidade e Subjetividade da Universidade Estadual de Ponta Grossa - UEPG, Ponta Grossa/PR. Doutora em Literatura pela UFSC. E-mail: kelipacheco@hotmail.com. O presente artigo é um formato mais condensado de um debate presente no livro Lima Barreto e a comunidade em exílio, editado pela Annablume, e lançado oficialmente em junho de 2013, no VII Ciclo de Estudos em Linguagem, UEPG/PR. 



\section{A INOVAÇÃO DO MAL ESCRITO: LIMA BARRETO E ROBERTO ARLT}

[...] Mas quantos outros, pela atração irresistível do centro, só podem desprender-se com uma violência sem harmonia, quantos deixam em sua esteira cicatrizes de feridas mal fechadas, os traços de suas sucessivas fugas, de seus regressos inconsolados, de seu vaivém aberrante. Os mais sinceros deixam ao abandono o que eles próprios abandonaram. Outros escondem as ruínas e essa dissimulação torna-se a única verdade de seus livros [...]

(BLANCHOT, 1987: 48-49)

No ensaio "Labirintos da biblioteca do pobre", Raúl Antelo evoca a crônica "A biblioteca", de Lima Barreto, em que o leitor diante do grandioso edifício da Biblioteca sente-se excluído, colocado à margem, e compara a situação deste leitor à própria condição de Lima Barreto escritor, uma vez que sua produção também é colocada fora da biblioteca nacional. Tal conjuntura, ainda segundo Antelo, seria reforçada e "recomendada pelos manuais e pela historiografia mais convencional” (2005: 90), o que faz a situação de exclusão perdurar por um longo tempo. 
Podemos pensar que a exclusão ocorreu porque a literatura de Lima Barreto parece colocar em risco a perspectiva daqueles que, a partir de uma leitura muito própria, utilizam-se da literatura para buscar constituir e fortalecer uma integração identitária e territorial coesa -, a título de exemplo podemos citar o estudo de Abel Barros Baptista (2003), quando escreve sobre a apropriação de parte da crítica brasileira da leitura de Machado de Assis, lendo a produção deste como se existisse uma preocupação com o projeto de solidificação de limites, de construção da literatura nacional. ${ }^{1}$

Diferente do que aconteceu com Machado, em que ocorreu uma apropriação da leitura, com Lima Barreto esta possibilidade de leitura crítica cerrada - que privilegia a pertença ao território e a busca por um traço identitário - parece se encontrar praticamente interditada, haja vista a presença da crítica incisiva e direta do escritor à nação e ao nacionalismo. O próprio Lima Barreto declara, sem rodeios: "Não sou um nacionalista". Esta frase aparece ao fim da crônica "A minha Alemanha", escrito que foi finalmente resgatado, em 2004, por Beatriz Resende e Rachel Valença. Para Resende, esta declaração final, assim tão cabal, seria o motivo que levaria à exclusão desta crônica da primeira edição de Obras Completas, de 1956 (2004: 13).

Assim nos parece sintomático, por exemplo, o fato de Antonio Candido, - no ensaio "Os olhos, a barca e o espelho", de A Educação pela noite \& outros ensaios - debruçar-se na leitura de um trecho do diário de Lima Barreto, deixando de lado sua literatura. Candido ressalta que esta última é resultado das circunstâncias da vida de Lima Barreto, o que caracterizaria a "concepção empenhada" da literatura do autor, e ainda favoreceria a "expressão escrita da personalidade", o que "pode ter contribuído para atrapalhar a realização plena do ficcionista”. Tal 'personalismo' de Lima Barreto, o tornaria, ainda para Candido, "um narrador menos bem realizado, sacudido entre altos e baixos, freqüentemente incapaz de transformar o sentimento e a ideia em algo propriamente criativo" (1987: 82-83).

Esta atribuição da crítica de que na narrativa de Lima Barreto e Roberto Arlt 'falta algo', gera um incômodo. Frequentemente este 'falta algo' é justificado como decorrente de uma 'má formação', de uma carência ou falta de

1 Para saber mais sobre este tópico, ver o artigo "Um estrangeiro lê Machado: uma crítica inoperante da instituição literária nacional”. (PACHECO, 2011: 13-21). 
tempo, visto que ambos escreviam como forma de sobrevivência. Tal pensamento se perpetuou, derivando em uma espécie de tradição crítica da leitura dos romances de Arlt e Lima que, num primeiro momento, proliferou em chave autobiográfica.

Ainda em vida ambos os autores tiveram que lidar com as críticas negativas. A título de exemplo, vale lembrar o que disse Elias Castelnuovo, quando recusou os originais de La vida puerca, primeiro título de El juguete rabioso, acerca da escritura de Arlt, segundo Martín Prieto:

Para Castelnuovo, decir que Arlt 'no sabía gramática significa un elogio. No sabía siquiera poner una coma para separar un párrafo de otro y difícilmente acertaba a colocar en su lugar una zeta o sacar de su sitio un hache'. Además, recuerda Catelnuovo, 'empleaba muchas palabras cuyo sentido ignoraba y otras que no se las podía encontrar en ningún diccionario de habla castellana, seducido únicamente por el embrujo de su sonoridad'. Por lo tanto, 'si le gustaba la música de un vocablo, solía intercalarlo en su léxico, a menudo sin haber asimilado aún su real significación, Describiendo el rostro de una virgen, por ejemplo, decía el cuévano de sus ojos, y describiendo las andanzas de una ramera, decía la desgraciada morcona. Y cuévano quiere decir canasto, y morcona no quiere decir nada. Y menos ramera. Probablemente quisiera decir moscona?. (PRIETO, 2006: 267)

Lima Barreto também sofrera o mesmo tipo de crítica. Como vemos no artigo publicado em A Notícia, em julho de 1916, onde Antonio Torres escreve: "O sr. Lima Barreto escreve mal, diga-se logo, escreve mal. Escreve mal neste sentido que a sua frase é mal cuidada, incorreta perante as soleníssimas regras da Gramática” (1916, apud PENTEADO, 2001).

Às acusações de escrever mal, Arlt responde: “Se dice de mí que escribo mal. Es posible. De cualquier manera, no tendría dificultad en citar a nume- 
rosa gente que escribe bien y a quienes únicamente leen correctos miembros de su familia" (ARLT s/d: 7). Ele defende ainda o exercício de uma literatura como um golpe de boxe, como um cross en la mandíbula. Lima Barreto, do mesmo modo, também procura elaborar uma escritura que esteja ao alcance do público. No prefácio do livro Histórias e Sonhos, temos a resposta do escritor para uma crítica que o acusava de utilizar os processos do jornalismo, à qual ele responde: "eu tento também executar esse ideal em uma língua inteligível a todos, para que todos possam chegar facilmente à compreensão daquilo a que cheguei através de tantas angústias" (1990: 16). E por este motivo esta literatura é como arma, agressiva, escreve Lima Barreto: "Não desejamos mais uma literatura contemplativa, o que raramente ela foi; (...). Não é isso que os nossos dias pedem; mas uma literatura militante para maior glória da nossa espécie na terra e mesmo no Céu" (1990: 16).

Para além do desejo de comunicação eficaz, o fazer literário era para o escritor brasileiro e também para o argentino um meio de ganhar a vida, Lima Barreto conciliava a função de funcionário público e de escritor de jornal para amparar a família. Arlt se dedicava a escrever para sua coluna diária no El Mundo, o que o sustentava, mas sem excessos. Esta dupla jornada, essa dedicação às artes e, ao mesmo tempo, à sobrevivência, suscita a discussão sobre "a relação entre o 'ordinário' do trabalho e a 'excepcionalidade’ artística”. É possível pensar sobre o que escreve Jacques Rancière, na última parte de $A$ partilha do sensível, em que remonta essa relação através de uma discussão platônica sobre a mímesis, uma vez que o fazedor de mímesis é um ser duplo que perturba a partilha do sensível, visto que na polis cada um só deve fazer uma coisa, exercer uma só função, fundamentada pela justificativa da 'ausência de tempo'.

A partir disto, o filósofo francês ainda pensará as relações entre o trabalho e a arte no decorrer da história, observando as mudanças de valor atribuídas a estes campos desde a antiguidade até as vanguardas dos anos 20.

Rancière então nos propõe que se pense o modo estético do pensamento ligado à idéia da partilha do sensível, o que vai mais além de um pensamento da arte. Além da promoção econômica do trabalho, não pode- 
mos esquecer que as lutas proletárias também tornaram o trabalho visível. E para Rancière, é preciso sair do esquema preguiçoso e absurdo que opõe o culto estético da arte pela arte à potência ascendente do trabalho operário. É como trabalho que a arte pode adquirir o caráter de atividade exclusiva. (...) O culto da arte supõe uma revalorização das capacidades ligadas à própria idéia de trabalho. (...) Qualquer que seja a especificidade dos circuitos econômicos nos quais se inserem, as práticas artísticas não constituem uma exceção as outras práticas. Elas representam e reconfiguram as partilhas dessas atividades (2005: 68-69).

Neste viés, nos parece que a idéia de se assumir o labor escritural como sinônimo de "operário das letras" - visto que é afirmada por Arlt e Lima a escritura como meio de ganhar a vida, como um trabalho comum que toma tempo, que os exaure -, coloca em jogo, como vimos com Rancière, a re-partilha do sensível, melhor dizendo, nesta concepção a literatura é posta em um corpo a corpo com as outras atividades. Contudo, nos parece que o incômodo derivado da idéia da escritura como moeda de troca imbrica a seguinte noção: a do ócio cultural como trabalho pago.

Então, o que em um senso comum é considerado ócio, o fazer artístico, passa a ter valor, provocando uma desestabilização, visto que insere a arte na partilha do sensível e, ao mesmo tempo, coloca em questão a própria noção de trabalho. Nesta concepção, a literatura só é trabalho à medida que vira moeda de troca, porém se tornar moeda de troca a faz ser pior, pobre, segundo a opinião de alguns, o que quer dizer, que tal noção ainda desprestigia não só o trabalho, mas também aquilo que o constitui: a fabricação e a produção, a relação entre o fazer e o ver.

Com relação a este aspecto, assemelhando-se ao que escreve Rancière - que procura introduzir o campo da arte no trabalho, desconfigurando-a como campo isolado -, está Josefina Ludmer, em "Literaturas postautónomas". Neste ensaio, a crítica procura compreender a literatura do presente, e escreve que estas se fundam sobre dois postulados. Um deles detecta que 
não há distinção entre o cultural e o ficcional, "la realidad [si se la piensa desde los medios, que la constituirían constantemente] es ficción y la ficción es realidad", mas produzem algo que a crítica nomeia de "realidadficción". O segundo postulado traça a ausência de fronteira entre a economia e a cultura. "El primer es que todo lo cultural [y literario] es económico y todo lo económico es cultural [y literario]" (2007). Daí passa a não ser mais crime assumir o literário, que agora é mais um trabalho, uma produção cultural, como um meio de sobrevivência. Porém, estes postulados já estavam configurados no passado, pois Roberto Arlt e Lima Barreto já os praticavam.

Contudo, ainda há a insistência de uma crítica em associar a atividade do escritor como estando além e acima de qualquer ideia de produção econômica, o que impossibilita a união do trabalho à arte, ou da arte como mais um trabalho. Neste passo, assumir-se jornalista e romancista supõe o prejuízo de uma das atividades.

A título de exemplo, recentemente Pablo Rocca traduziu para o espanhol dez contos de Lima Barreto, que irão compor o $11^{\circ}$ número da coleção "Lectores de Banda Oriental”, publicada no Uruguai, e comenta em entrevista sobre a união da pressa e da paixão pela escrita. Rocca cita a reelaboração de Clara dos Anjos, de Lima Barreto, que passou de conto à novela, mas nessa dinâmica, para Rocca, "sai, por vezes, um resultado fraco ou uma força notável. Algo como uma exigência entre mercado de escritura, demanda de leitores e 'prepotencia de trabajo', como diria seu 'parente', não tão distante, Roberto Arlt" (2008).

Rocca se limita ao ver no erro um simples "mal acabar", sendo este o resultado da demanda urgente que estes "pobres escritores" tinham em "ganhar a vida" e fazer dinheiro. Nesta entrevista, torna-se evidente que Rocca segue uma tradição crítica de leitura da obra de Roberto Arlt, e procurar ainda encaixar Lima Barreto nesta mesma tradição de leitura.

Ricardo Piglia publicou o artigo "Roberto Arlt, una crítica de la economia literaria” pela primeira vez em março de 1973, no número 29 da revista Los Libros. Nele podemos ler:

¿Escriben bien porque nadie nos lee? En realidad, lo que sucede es que nadie paga por esa lectura: leídos en 
familia, no hay lazos económicos, el dinero está excluido. Arlt invierte los valores de esa moral aristocrática que se niega a reconocer las determinaciones económicas que rigen toda lectura, los códigos de clase que deciden la circulación y la apropiación literarias. Entre el texto y el lector no habría ninguna interferencia: la cultura sería justamente ese 'vacío' donde se disuelve cualquier relación material para sitio del trabajo productivo que la mantiene. En Arlt, lo contrario, escribir bien es hacerse pagar, en el estilo, un cierto 'bien' que alguien es capaz de comprar. Solo a costa del lector se puede costear el interés por la literatura: ser leído es saldar una deuda, encontrar el sentido de ese trabajo 'misterioso', 'inefable' que no tiene explicación en una sociedad que funda su razón de ganancia (PÍGLIA, 2004: 2-3).

Este artigo de Piglia alcançou uma inusitada eficácia crítica e algumas das hipóteses e estratégias nele desenvolvidas permanecem até hoje sendo reproduzidas, como podemos ver nesta entrevista recente de Rocca. Vale acrescentar que nesta leitura de Piglia temos incorporada a visão do marxismo clássico que vê o econômico como determinante, de modo que a cultura está aí como uma simples marionete a ser regida pelo dinheiro. O lugar de Arlt na literatura, a partir desta leitura de Piglia, seria o de nos fazer ver, de nos 'iluminar' esta sobredeterminação econômica que rege nossa sociedade. Idéia que se opõe ao pensamento de Rancière que visualiza o trabalho, e o que lhe circula, como uma atividade que torna visível, que partilha e re- partilha o sensível. Neste viés, ao tomarmos a arte como mais um trabalho se abre a possibilidade de reconfiguração da cultura, agora não mais tomada como um campo vazio, onde se impinge valores, como difunde Piglia.

Mas e o que ocorre com essa relação quando não se respeita as normas gramaticais, quando se "escreve mal" tal como o fazem Lima Barreto e Roberto Arlt? No erro, ou no "mal escrever", César Aira, em "La innovación", consegue detectar um importante e interessante questionamento que 
abre uma linha de fuga da instituição literária e do próprio mito de autor. "Al fondo de la literatura mala, para encontrar la buena, o la nueva, o la buena”. A própria escritura de Aira, como novelista, está aí incluída, contra a eficácia da literatura que funcione bem.

Essa aparição do mal acabado, do ruim, provoca um questionamento na própria literatura ligada ao "bom gosto". Uma vez que por trás do que se chama "bom gosto", sabemos que figura o institucional, a norma e a gramática e, portanto, a lei e o Estado. Roland Barthes chama a atenção para o caráter obrigatório da ortografia, que nos policia e que impede o escritor de gozar sua escritura. Barthes defende uma idéia de rasura, o que desvincularia a escrita do aparelho do Estado, na qual ao autor não cabe mais a função de ser um policial da escrita, pois ao produzir rasura acaba por livrar-nos de toda regra (1988: 60-61).

Maurice Blanchot, por sua vez, e ao ler a obra de Franz Kafka, vê justamente nessas marcas do mal feito, ou de um desfecho não ideal, que o próprio Kafka se acusa em diário, uma justificação plena, uma vez que a presença dessas marcas comovem o leitor pois o colocam diante do autor "que se afastou dela apressadamente demais, na incapacidade de terminá-la, no temor de, senão a concluísse, não poder voltar a luz do dia”. (1987: 48).

E sabemos que Arlt e Lima não paravam de escrever, "un libro tras outro, y que 'los eunucos bufen", como dizia Arlt na abertura de Los Lanzallamas. Lima Barreto registra em seu Diário Íntimo que sempre se via "escrevendo em explosões".

Neste passo, compreende-se a proposta de Josefina Ludmer ao pensar nos romances recentes como sendo impossíveis de serem classificados. Não importa mais se são bons ou ruins, ou se são ou não literatura, visto que se situam numa fronteira, "como si estuvieran 'en êxodo"'. Segundo Ludmer, estas produções recentes aparecem como literatura, têm o formato e trazem o nome do autor na capa, mas não se pode lê-las com base em categorias literárias: autor, obra, estilo, etc. Assim, torna-se impossível qualquer atribuição de valor. São literaturas que solicitam ao mesmo tempo em que suspendem o poder de julgamento. Por isso, por não fazerem mais parte de um campo autônomo, Ludmer chama esta nova literatura de pós-autônoma. 
Esta literatura conta uma experiência verbal do subsolo "de ciertos sujetos que se definen afuera y adentro em relación com territórios" (LUDMER, 2007). Com efeito, torna-se impossível não identificar na literatura de Roberto Arlt e Lima Barreto fortes traços da literatura produzida no presente. Contudo, é preciso salientar que estes problemas já estavam colocados no passado, uma vez que, como exposto acima, estes escritores já solicitavam algo que somente hoje se reconhece e, finalmente, sobre o qual criticamente se reflete, isto é, o fim da era da literatura como esfera auto-suficiente.

\section{REFERÊNCIAS BIBLIOGRÁFICAS}

ANTELO, R. Labirintos da biblioteca do pobre. Outra Travessia (UFSC), Revista de Pós-graduação em Literatura. Florianópolis, n. 4, p.91-103, 2005.

ARLT, R. Palabras del autor. In: Los lanzallamas. Barcelona: Montesinos, s/d.

BAPTISTA, A. A Formação do Nome, duas interrogações sobre Machado de Assis. São Paulo: Unicamp, 2003.

BARRETO, L. Amplius! In: Prefácio - Histórias e Sonhos. Rio de Janeiro: Garnier, 1990.

BARTHES, R. Concedamos a liberdade de traçar. In: O Rumor da língua. Trad. Mario Laranjeira. São Paulo: Brasiliense, 1988.

BLANCHOT, M. A obra e a fala errante. In: O espaço literário. Rio de Janeiro: Rocco, 1987.

CANDIDO, A. Os olhos, a barca, o espelho. In: A Educação pela noite \& outros ensaios. São Paulo: Ática, 1987.

LUDMER, J. Literaturas postautónomas. In: Ciberletras. Disponível em: $<$ http:// www.lehman.edu/ciberletras/v17/ludmer.htm> Acesso em: 25 set. 2007. 
PACHECO, Keli C. Um estrangeiro lê Machado: uma crítica inoperante da instituição literária nacional. REALIS - Revista de Estudos AntiUtilitaristas e PosColoniais, v. 1, p. 13-21, 2011.

PENTEADO, A. Á. Leitura e percepção estética. Espéculo. Universidad Complutense de Madrid, n.18, 2001. Disponível em:<http://www.ucm.es/info/especulo/numero18/limabar2.html>. Acesso em: 23 jun. 2007.

PIGLIA, Ricardo. Roberto Arlt, una crítica de la economia literária. In: Ficciones Argentinas: antologia de lecturas críticas. Buenos Aires: Norma, 2004.

PIETRO, M. Breve historia de la literatura argentina. Buenos Aires: Aguilar, Altea, Taurus, Alfaguara, 2006.

RANCIÈRE, J. A partilha do sensível (Estética e política). Trad. Mônica Costa Netto, São Paulo: ed. 34/Exo, 2005.

RESENDE, B. Sonhos e mágoas de um povo. In: Toda Crônica. RESENDE, B. \& VALENÇA, R. (Org.). Rio de Janeiro: Agir, 2004.

ROCCA, P. Lima Barreto em terras estrangeiras. In: Jornal Diário Catarinense-Cultura. N. 8092. 07 de Junho de 2008. Capa do suplemento Cultura. 